\title{
Considerações acerca do desenvolvimento nacional na década de 1950
}

Marlise Regina Meyrer ${ }^{1}$

\section{Resumo}

Nos anos 1950, o desenvolvimento compôs o imaginário no qual o Brasil aparecia como país do futuro, moderno, progressista e pleno de possibilidades. Economistas, intelectuais, políticos passaram a discutir, planejar e implementar ações que levassem o país o mais rapidamente possível ao futuro. Partindo das diferentes acepções do conceito de desenvolvimento, o artigo discute os diferentes projetos para o desenvolvimento brasileiro, na década de cinquenta, momento em que esta questão ocupava a centralidade nos discursos acerca da nação.

Palavras-chaves: História do Brasil. Desenvolvimento nacional. Economia brasileira.

\begin{abstract}
In the 1950s, the development in which composed the Brazil imaginary appeared as the country of the future, modern, progressive and full of possibilities. Economists, intellectuals, politicians began to discuss, plan and implement actions that would lead the country as soon as possible the future. Starting from the different meanings of the concept of development, the paper discusses the different projects for Brazilian development in the fifties, when this question occupied the centrality in discourses of nation.
\end{abstract}

Keywords: Brazilian History. National development. Brazilian economy.

\section{Introdução}

Os anos 50 foram o período em que, no Brasil, o discurso em torno do desenvolvimento nacional foi posto na agenda, sobretudo na segunda metade da década. Havia um consenso entre elites políticas e econômicas, intelectuais e opinião pública de que o país vivenciava profundas transformações e, mesmo passando por crises econômicas conjunturais, ele estava "em desenvolvimento", fase intermediária que conduziria a estrutura

${ }_{1}^{1}$ Doutora em História pela PUCRS e professora do PPGH da Universidade de Passo Fundo/RS. meyrer_nh@hotmail.com 
capitalista plenamente desenvolvida. Todos os segmentos estavam preocupados com a forma mais adequada de realizá-lo, sendo que, no final da década, "[...] são incorporadas definitivamente as ideias desenvolvimentistas, pois as elites e o governo tinham ampla consciência das mudanças que haviam ocorrido dentro do país ao longo dos últimos anos" (GORENDER, 1983, p. 39).

As ideias que permearam o imaginário nacional dos anos 50 eram as de que havia no Brasil "[...] a crença na transformação do presente com o objetivo de construção de um futuro alternativo ao próprio presente" (NEVES, 1976, p. 109). Esse sentimento alimentou a utopia desenvolvimentista que tomou conta do país na época, culminando com o Plano de Metas de JK, que propunha acelerar o tempo histórico, anunciando a chegada do futuro.

Entretanto, o desenvolvimento, ou melhor, o modelo proposto não era único. Os amplos debates referentes a essa questão, sobretudo nos anos 50, decorriam exatamente das diferentes visões sobre o tema, resultando em distintos projetos. Ao falarmos, portanto, em desenvolvimento nacional, faz-se necessário conhecer as variadas acepções do termo e identificar a influência das diferentes correntes de pensamento que permearam o chamado projeto desenvolvimentista brasileiro dos anos 50 . Nesse sentido, nos propomos, no presente artigo, esclarecer alguns pontos sobre essa questão.

\section{Modelos de desenvolvimento}

Mundialmente, o contexto econômico da década de 50 foi definido por Hobsbawn (1995) como a Era de Ouro. O mundo industrial expandia-se por toda parte. 0 autor aponta para o desenvolvimento espetacular dos países chamados "em recente industrialização", tendo diminuído acentuadamente o número de nações dependentes da agricultura para financiar suas importações do resto do mundo. A economia mundial crescia a uma taxa explosiva, e a produção de manufaturados quadruplicou entre a década de 1950 e o começo da de 1970.

O capitalismo mundial desenvolveu-se em torno dos Estados Unidos, que, entre os anos 1950 e 1970, quadruplicaram as suas exportações para o resto do mundo, mas também se tornaram um importante importador de bens de consumo. Em 1952, a eleição de Eisenhower para a presidência dos Estados Unidos marcou a culminância desse processo. Segundo Muniz Bandeira (1973), Oswaldo Aranha teria se referido a Eisenhower como sendo manipulado pelos grandes banqueiros, industriais e comerciantes norte-americanos. Para ele, o período que se inaugurava seria caracterizado pelo domínio de Wall Strett sobre o Estado ("O capitalismo no poder não conhece limitações, sobremodo as de ordem internacional").

As multinacionais americanas aumentaram suas filiais estrangeiras de cerca de 7,5 mil, em 1950, para mais de 23 mil em 1966. Contudo, as empresas de outros países as foram seguindo cada vez mais, sendo sua principal função a de "internalizar mercados ignorando fronteiras nacionais", tornarem-se independentes de fronteiras nacionais, isto é, tornarem-se independentes do Estado e de seu território. Assim, "[...] na América Latina, já em 1950, trezentas filiais de empresas norte-americanas respondiam por 90\% das inversões realizadas pelas empresas estadunidenses na região [...]" (FURTADO, 1961, p. 53). 
No Brasil, a revista $O$ Cruzeiro (a principal revista em nível nacional da época) saudava este processo acolhendo, em suas páginas, as empresas estrangeiras, especialmente as norte-americanas, seja através de reportagens pagas ou publicidade explícita. Difundia, assim, o americam way, ${ }^{2}$ através da propaganda e do cinema de Hollywood.

Os produtos eram anunciados por atrizes de Hollywood, que ditavam os novos padrões de beleza e da moda. Assim, para ter "dentes perfeitos e um sorriso que seduz" Kolynos; "fazer a barba com maior suavidade e rapidez" - Gillette; ter o "frescor juvenil da cútis de Elizabeth Taylor" - Sabonete Lever; "dores, gripes e resfriados - Melhoral, "que é melhor e não faz mal"; "saúde e energia de seus filhos" - Toddy ou Aveia Quaker; "cútis aveludada como pétala de rosa" - Sabonete Palmolive; "proteger o motor de seu carro" - Shell; "manter a alegria da mulher "mesmo naqueles dias" - Modess; "higiene do bebê" - Johson e Johnson, entre tantos outros produtos de bens de consumo, oferecidos aos leitores, que chegavam ao consumidor através dos anúncios.

Nos anos de 1950, caracterizados pelo auge do pensamento desenvolvimentista, algumas empresas preocuparam-se em enfatizar a sua grande contribuição para o desenvolvimento do país. Assim, o público de $O$ Cruzeiro também podia ler, através da publicidade, como a instalação de fábricas estrangeiras, como a Coca-Cola, por exemplo, auxiliavam no desenvolvimento de outras indústrias nacionais, pois, afinal, "ela (a tampinha) também é brasileira". ${ }^{3}$ A Ford publicava diferentes anúncios tematizando o desenvolvimento do Brasil, país no qual ela sempre confiou, antevendo o seu "futuro grandioso" ${ }^{\prime 4}$.

Esta entrada maciça de produtos e capital estrangeiro já vinha se intensificando desde os anos 40; entretanto, o contexto da Guerra Fria, obrigando o alinhamento dos países a uma das potências dominantes, limitava sua soberania. O período anterior dera aos países latino-americanos um certo poder de barganha em relação às grandes potências, sendo que, naquele momento, os Estados Unidos haviam assumido uma postura de franca colaboração governo a governo, inclusive, enviando missões de amparo às iniciativas, para desenvolver a indústria brasileira, como a Missão Cooke - 1943. Finda a Guerra, porém, os governos dos países não mais puderam negociar entre si, mas tiveram de obedecer a uma série de instituições econômicas criadas pelas principais potências, tendo, à frente, os EUA, a partir da Conferência de Bretton Woods, entre as quais o FMI e o Banco Mundial, cujo objetivo principal era "promover uma ordem econômica liberal no plano internacional, que revertesse o protecionismo vigente no período anterior a segunda guerra" (SALLUM JÚNIOR, 2000, p. 143).

Em meio a tais questões, muitos países latino-americanos passaram a discutir, cada vez mais, o desenvolvimento nacional como forma de integração econômica in-

\footnotetext{
${ }^{2}$ Expressão comumente utilizada para referir-se ao típico modo de vida norte-americano.

${ }^{3}$ Frase referente a um anúncio veiculado na década de cinquenta em que a tampinha do refrigerante ganhava mais evidência do que o produto em si, destacando que a sua produção era feita no Brasil com a contribuição de Volta Redonda. Da mesma forma, outros anúncios se referiam à contribuição da Coca-Cola para o desenvolvimento nacional, em vários outros setores, como o da construção de carrocerias para o transporte de suas mercadorias e, ligado a este, o setor madeireiro.

${ }^{4}$ A Ford publicava frequentemente anúncios de página inteira, às vezes duas, explicando a atuação da empresa no país. Descrevia sua contribuição para o desenvolvimento brasileiro e sua crença no futuro da nação. Evidenciava sua importância no transporte de mercadorias, nos motores das indústrias, nas máquinas agrícolas, entre outros.
} 
ternacional. No Brasil, este período constituiu-se na etapa final da industrialização, cujo processo havia se iniciado nos anos trinta. As forças produtivas estavam plenamente constituídas e cabia ao governo articular a grande empresa estrangeira, a privada nacional e a pública, a fim de promover o desenvolvimento e inserir o país, definitivamente e de forma mais vantajosa, na ordem econômica capitalista ocidental.

Devés Valdés (2003) diz que o conceito de desenvolvimento é provavelmente o mais utilizado no pensamento latino-americano, na segunda metade do século XX, tornando-se um dos pilares do que hoje conhecemos como pensamento latino-americano. Entretanto o conceito, à medida que se integrou aos diferentes discursos, foi adquirindo matizes e significações diversas, sendo que, no período pós-guerra, a característica predominante foi a modernizadora. Destaca ainda que, embora muitas vezes desenvolvimento e crescimento econômico tenham sido utilizados como sinônimos, tecnicamente o conceito é muito mais amplo, podendo ser definido como:

crecimiento auto sostenido que envuelve durante um período relativamente largo al conjunto de uma sociedad: es también um proceso donde confluyen, em primer lugar, elementos econômicos, que iran aconpanãdos por factores sociales, políticos y culturales: también se lo ha idenficado com uma mejoria em las condiciones de vida de las massas. Em términos más precisos se lo há asociado a la industrialización, al progreso tecnológico-científico, a la urbanización, al aumento Del ingreso per capita y a mejoras en las condiciones de vida: alimentación, vivienda, educación, salud (DEVÉS VALDÉS, 2003, p. 22).

Esta amplitude do conceito faz com que ele esteja presente em várias escolas de diferentes tendências, adquirindo significações distintas. Devés Valdés (2003) diz ainda que, nos anos de 1950, o conceito foi incorporado por correntes, partidos e personagens que o foram integrando ao seu acervo conceitual, adaptando-o.

Para Bielschowski (1996), o desenvolvimentismo consiste na ideologia de transformação da sociedade brasileira definida pelo projeto econômico que tem por base uma industrialização planejada e dirigida pelo Estado, sendo o conceito mais adequado para entender o pensamento econômico brasileiro da época (anos 1950), constituindo a ideologia central, a partir da qual se situavam as diferentes correntes de pensamento nacionais. Ele as divide da seguinte forma: a neoliberal, a desenvolvimentista - subdividida em três variantes - e a socialista.

A corrente neoliberal, em oposição às propostas desenvolvimentistas, representava toda a tradição da ideologia liberal brasileira, vigente desde o século XIX, e que se via ameaçada diante do novo modelo de "desenvolvimento para dentro", podendo ser caracterizada pelo pensamento de Eugenio Gudin e Octávio Gouveia de Bulhões. O grupo defendia a redução da participação do Estado na economia, as políticas de equilíbrio monetário e financeiro e, em geral, não apoiava os projetos de industrialização. Para essa corrente, o principal instrumento do desenvolvimento era o livre mercado e não a indústria, como pensavam os nacionalistas. A industrialização dar-se-ia de forma lenta e gradativa como resultado do progresso técnico do setor primário-exportador. Ainda para o mesmo grupo, o principal recurso para o desenvolvimento econômico das nações "atrasadas" deveria ser a atração do capital estrangeiro. Essa, aliás, foi a questão mais polêmica relacionada ao debate desenvolvimentista brasileiro, sendo que, para os nacio- 
nalistas, era símbolo ideológico do velho imperialismo (BIELSCHOWSKI (1996).

Já a corrente desenvolvimentista é dividida pelo autor em três grupos.

- O primeiro deles, o antiliberal e desenvolvimentista do setor privado, defendia um projeto de industrialização planejada com base no capital nacional. Inicia-se na década de 1930, com a insipiência de uma elite industrial nacional cuja liderança pode ser atribuída, pioneiramente, a Roberto Simonsen, sendo que seu pensamento teve continuidade entre as elites industriais brasileiras até o final dos anos 50 . 0 assunto mais polêmico do grupo foi o da participação direta do Estado e do capital estrangeiro. De um modo geral, defendiam a participação do Estado, preferencialmente de forma indireta, criando condições favoráveis ao desenvolvimento das empresas privadas. Da mesma forma, as questões referentes ao capital estrangeiro vinculavam-se ao objetivo principal dos empresários nacionais, que era o de evitar a concorrência desigual a esse capital.

- O segundo eram os desenvolvimentistas "não nacionalistas" do setor público. Pouco numeroso, mas ativo e influente, era formado por economistas que acreditavam que o capital estrangeiro tinha uma ampla contribuição a dar ao processo de industrialização do país. Muitos deles aglutinados no projeto que instituiu a Comissão Mista e o BNDE em 1951, como Horácio Lafer e Roberto Campos, este último figura importante no debate brasileiro dos anos 50 e quem melhor representou o grupo. Apoiavam o ponto fundamental do projeto desenvolvimentista - a industrialização planejada -, não descartavam totalmente a participação estatal, mas preferiam o capital estrangeiro, especialmente nas áreas de infraestrutura. Esse grupo aproximava-se dos liberais, porém se afastava em pontos cruciais, como a crença de que a industrialização seria a via pela qual se daria a superação do atraso, defendida por Campos e negada por Gudim. A posição de Campos, a partir de meados dos anos 50, pode assim ser definida:

[...] a insuficiência de capitais, de Know-How e de capacidade para importar faziam com que os interesses da nação envolvessem uma política de atração de capitais externos. A participação do Estado em empreendimentos produtivos deveria ser tolerada, mas apenas naqueles projetos indispensáveis, em relação aos quais, momentaneamente, não houvesse interesse privado nacional ou estrangeiro em investir. $\mathrm{E}$, mesmo o capital privado nacional deveria evitar certos ramos de investimento (BIELSCHOWSKI, 1996, p. 122).

- O terceiro grupo era o dos desenvolvimentistas nacionalistas, que tinha como principal característica a defesa da intervenção do Estado na economia, através de políticas de apoio à industrialização aliadas a um planejamento, incluindo investimentos estatais em setores básicos da economia. Eram céticos quanto às possibilidades do capital estrangeiro contribuir para a estruturação da indústria nacional, particularmente nos setores de infraestrutura. Entretanto, nos setores não estratégicos, o capital estrangeiro seria bem-vindo, porém de forma controlada, sobretudo quanto à remessa de lucros.

Um aspecto que os diferenciava dos demais desenvolvimentistas era sua interpretação estruturalista do desenvolvimento, desconsiderando, em geral, ações de curto prazo para o controle inflacionário. Distinguiam-se, também, por inserir, ao menos em seu discurso, medidas econômicas de cunho social, como desemprego, pobreza e atraso cultural da população brasileira, postura que, no entanto, não se constituiu em elemento-chave no seu projeto desenvolvimentista. O grande divulgador de tais idéias, no Bra- 
sil, foi Celso Furtado, principal representante no país das ideias da CEPAL .

Uma última corrente é definida como socialista. Agrupava elementos que, de um modo geral, possuíam algum vínculo com o Partido Comunista Brasileiro. Esse grupo, de certo modo, também era "desenvolvimentista", na medida em que defendia a industrialização e a intervenção estatal. Era constituído, em parte, por nacionalistas, porém mais radicais. Enquanto que para os outros grupos a industrialização era discutida como via para o pleno desenvolvimento capitalista, para o grupo em questão, ela seria o meio pelo qual se chegaria à transição para o socialismo. Os problemas brasileiros eram tratados, de um modo geral, como decorrentes do imperialismo e da estrutura agrária.

Ainda de acordo com Bielschowski (1996), os pontos principais do desenvolvimentismo dos anos 1950 são a industrialização integral, como via de superação da pobreza e do subdesenvolvimento brasileiro, sendo que essa somente poderá ser alcançada através do planejamento estatal; o Estado deve ordenar também a execução da expansão, captando e orientando recursos financeiros e promovendo investimentos diretos naqueles setores em que a iniciativa privada seja insuficiente. Entretanto, este predomínio não foi absoluto. Conforme o mesmo autor, o ideário desenvolvimentista passou, nos anos cinquenta, por um processo de amadurecimento que chegaria ao seu apogeu somente a partir de 1955-1956. Esse processo esteve vinculado à conjuntura econômica do período, marcada, ao mesmo tempo, por altas taxas de crescimento e por uma crise decorrente, em parte, desse acelerado crescimento.

Desde os anos quarenta, o Brasil vinha apresentando um elevado índice de crescimento, que teve um notável aumento entre os anos de 1950-1954. Este incremento decorreu, em parte, pela alta dos preços do café no mercado externo, bem como pela entrada de capitais estrangeiros. Segundo Malan (1995, p. 80), as exportações brasileiras apresentaram acentuada oscilação, que se deveu basicamente ao café, que "representou em média mais de $60 \%$ das exportações totais do Brasil no período". Não sendo de se estranhar, portanto, conforme o autor, que "a política cafeeira estivesse no centro do debate sobre o desequilibro do balanço de pagamentos brasileiro [...]". O autor ainda diz ainda que os preços do café, em dólares, haviam subido, entre 1945 e 1954, cerca de três vezes e meia, em termos reais.

Entretanto o crescimento não esteve vinculado somente a fatores externos, mas também internos. Entre 1948 e 1954, diminuiu a participação do comércio exterior na renda nacional, e houve um fortalecimento da produção para o mercado interno. No setor agrícola, embora a produção destinada à exportação tenha diminuído, a produção destinada ao mercado interno teve um incremento. A indústria manteve elevados índices de crescimento; entretanto, ainda não conseguia expandir-se sem a importação de equipamentos e tecnologia, o que mantinha o nível das importações em alta, decorrentes do aumento do seu valor. Estes dois fatores: queda nas exportações e aumento no valor das importações resultaram na diminuição da capacidade de importar, uma vez

\footnotetext{
${ }^{5}$ A CEPAL veio a ser o principal foro para discussão e defesa dos interesses latino-americanos, que produzia estudos anuais sobre o desenvolvimento da região, com ênfase na necessidade de industrialização e, sobretudo, nas formas de superação do atraso dos países periféricos. Suas idéias norteariam toda a discussão conceitual acerca dos planos de desenvolvimento latinoamericano na década de 50 . O desenvolvimento cepalino baseia-se na industrialização através de um planejamento estatal consciente, conforme Silva (2004, p. 54).
} 
que essa era determinada pelas exportações.

A partir de 1954, a economia brasileira encontrou-se em situação peculiar [...] Sua taxa 'necessária' de crescimento - taxa de crescimento correspondente a uma situação de plena ocupação da capacidade já instalada - é extremamente alta e exige uma forte complementação de recursos externos. Com efeito, a plena ocupação da capacidade instalada requer volumosas importações de certos produtos intermediários e de equipamentos. Como os produtos importados o são a preços relativamente altos, em razão da estreiteza da capacidade de importar, tornam-se muito rentáveis as inversões na substituição de importações. Mas, para substituir importações, requerem-se mais equipamentos importados, sendo necessário reduzir as importações antes referidas para abrir espaço às novas. Criou-se, desta forma, uma situação peculiar de desequilíbrio entre a capacidade para importar e o volume de importações necessárias para manter operando as instalações existentes e o correspondente volume desejado de investimentos (FURTADO, 1961, p. 241-242).

Esta avaliação era feita pelos principais grupos de discussão na época: BNDE e grupo Misto BNDE-CEPAL. Para Cardoso (1978), as dificuldades econômicas, decorrentes do processo acelerado de desenvolvimento com que o país se defronta em meados da década de 1950, impõem a necessidade de adoção de políticas mais sistemáticas de desenvolvimento, para o qual irão contribuir os estudos realizados pela CEPAL e pelo BNDE, destacando-se os trabalhos do Grupo Misto BNDE-CEPAL (1953-1955). Também contribuem as análises da Fundação Getúlio Vargas, principalmente através da revista Conjuntura Econômica. "O estatuto científico a elas atribuído permitiu que tivessem, através das constatações e projeções que faziam, a maior influência nas definições ideológicas, na articulação das relações de forças do período e, consequentemente, na programação governamental". Também, Bielschowski (1996, p. 368) diz que a conjuntura político-econômica do período (1953-1955) era “[...] propícia a que os intelectuais explicitassem suas preferências e definissem seus projetos de desenvolvimento. Sobressaía com nitidez, nesse contexto histórico, a orientação política dos debatedores da 'crise' brasileira". O mesmo autor acrescenta outros núcleos de discussão à lista de Cardoso (1978): o Departamento Econômico do Conselho Nacional de Economia (CNE), que, assim como a Fundação Getúlio Vargas (FGV), concentrava a tendência neoliberal; o Instituto Brasileiro de Economia, Sociologia e Política (IBESP) que, em 1956, torna-se o Instituto Superior de Estudos Brasileiros (ISEB).

O mesmo diagnóstico aponta para uma reversão na tendência de crescimento a partir de 1955. De acordo com essas avaliações, indícios de que a situação favorável da economia começava a se reverter já eram visíveis em 1955. A produção para exportação aumentou mais do que a para o mercado interno, fortalecendo novamente o setor tradicionalmente mais importante - o exportador. Paralelamente, ocorria uma diminuição do ritmo de crescimento na indústria. Portanto, mesmo com uma política cambial que beneficiava a indústria de equipamentos, a perspectiva era de redução do setor. ${ }^{6}$

A avaliação, tanto do Grupo Misto, quanto do BNDE, era de que, por ter se apoiado em fatores aleatórios - melhora nos termos de intercâmbio - o crescimento não

${ }^{6}$ Entre 1948 e 1953, vigoraram medidas de controle quantitativo das importações que favoreceram o setor indústria através do subsídio implícito às importações de matérias-primas e equipamentos (FURTADO, 1961, p. 239). 
conseguiria manter-se. A análise do BNDE, citada por Cardoso (1978, p. 402), diz que "a alteração da estrutura econômica brasileira determinada por estas condições externas extraordinárias não poderá conservar-se, uma vez cessada a atuação dos fatores que lhe deram origem". No mesmo sentido, o prognóstico do Grupo Misto BNDE-CEPAL afirma:

A deterioração na relação dos preços de intercâmbio - já manifestada fortemente em 1955 - assim como a carga dos recentes compromissos financeiros poderão inverter os termos daquela discrepância, passando a oferta interna a crescer menos que a produção (CARDOSO, 1978, p. 402).

O ano de 1955 mostra-se um período importante para essas discussões, na medida em que se evidencia, no período, uma crise de crescimento ${ }^{7}$ que se torna base para a política de desenvolvimento a ser adotada pelo novo governo. Renova-se a discussão nacionalistas versus entreguistas, travada, na década de 1940, entre Roberto Simonsen, líder empresarial, defensor do intervencionismo desenvolvimentista e da industrialização baseada no capital nacional, e Eugênio Gudin, professor universitário que pregava o desenvolvimento orgânico e a necessidade de capital estrangeiro, e não professava a superioridade da indústria frente à agricultura Na segunda metade dos anos 1950 essas divergências podem ser sintetizadas no confronto entre neoliberalismo e desenvolvimentismo que deram origem à discussão, no Brasil, entre os chamados monetaristas e os estruturalistas.

Os estruturalistas eram representados, sobretudo, pelo grupo da CEPAL e do IBESP, entre os quais estavam Celso Furtado e Hélio Jaquaribe. Entendiam que a crise conjuntural e a alta inflação decorriam da estrutura econômica herdada do passado, e a sua solução estava num planejamento geral da economia a longo prazo. Os monetaristas, por sua vez, defendiam medidas mais ortodoxas no combate à inflação e medidas para a atração de capitais externos. Podemos citar como representantes dessa corrente Eugenio Gudin, José Maria Whitaker e Roberto Campos. Para os primeiros, a inflação é decorrente da crise, e, para os segundos, a crise decorre da inflação, levando ao desequilíbrio. PINHO (1986, p. 145) assinala que "[...] as duas interpretações analíticas divergiam não só nos enfoques dos problemas estruturais e conjunturais, como também sobre o processo inflacionário, o uso de capital estrangeiro e o papel do Estado na vida econômica [...]".

Cardoso (1978, p. 400) enfatiza as propostas analíticas elaboradas pelo BNDE e pelo Grupo Misto BNDE-CEPAL. Essas análises, de um modo geral, apontam que o problema central para o desenvolvimento é o investimento. A solução estaria na elevação da taxa de poupança, através da diminuição dos gastos públicos; melhoria na produtividade, a partir da utilização de técnicas mais eficientes; e entrada de recursos externos, para a qual seriam necessárias medidas atrativas. Enfatiza-se, ainda, a necessidade de aumentar a exportação, o componente principal da renda nacional, através de uma política cambial adequada. Segundo a autora, O BNDE teria uma visão mais otimista em relação às possibilidades do desenvolvimento espontâneo, não intervencionista, enquanto

\footnotetext{
${ }^{7}$ BIELSCHOWSKY (1996, p. 372), ao analisar o triênio 1953-1955, diz que "havia algo próximo a um consenso de que se vivia uma 'crise de crescimento'." Para o autor, embora os desenvolvimentistas nacionalistas preferiam a idéia de crise estrutural, assim como os liberais, identificavam no período uma crise de investimentos decorrentes do ritmo de crescimento.
} 
para o Grupo Misto seria necessária a coordenação efetiva do Estado.

Essas discussões se intensificavam na medida em que o crescimento mostrava-se ameaçado pela conjuntura de crise. A ameaça ganharia consistência a partir dos prognósticos elaborados pelas duas Instituições citadas, que passam a discutir a política a ser adotada, a fim de dar continuidade ao crescimento, delineando-se as diretrizes do planejamento.

Como o principal fator de crescimento foram as relações dos preços de intercâmbio, sua deterioração é o que preocupa. O desenvolvimento passa a depender, então, de políticas protecionistas compensatórias. Caindo a entrada de capitais do setor exportador, o capital estrangeiro torna-se indispensável para substituir essa renda para o desenvolvimento industrial. Nesse sentido é criada, em 1955, a Instrução 113 da SUMOC, liberando a entrada e saída de capitais externos no país. Desde então, a tendência à mudança estrutural da economia volta a ser fortalecida, sendo que a entrada de capital estrangeiro passa a fornecer à indústria o capital de que ela necessita.

O período caracteriza um amadurecimento do debate sobre a industrialização planejada. As inúmeras estatísticas, cada vez mais abundantes e divulgadas, conquistam as elites intelectuais, técnicas e políticas do país para a realidade dessa transformação (da estrutura agroexportadora para a industrial). O momento, para o autor, não era propício para os liberais contestarem o significado do avanço decorrente da industrialização, sendo que as críticas passaram a se concentrar no combate à intervenção estatal na economia e à política artificial de preços (BIELSCHOWSKY, 1996).

É a partir da necessidade de um esforço para recuperação da economia que se insere o desenvolvimentismo de JK. O seu governo dá continuidade ao incentivo do desenvolvimento industrial associado, ${ }^{8}$ enquanto a agricultura perde a hegemonia. 0 capital estrangeiro passa a ser fundamental neste modelo de desenvolvimento, que se distancia da forma clássica de nacionalismo. Ele propõe um nacionalismo racional e técnico voltado para o desenvolvimento econômico. A soberania passa a estar vinculada diretamente à prosperidade, e esta depende dos recursos criados no país, independentemente destes serem nacionais ou internacionais. Prega, de fato, a incorporação do capital estrangeiro ao processo interno de produção no país (CARDOSO, 1978).

Ao discutir o caráter ideológico do desenvolvimento no período de JK, Cardoso (1978) diz que este se ancora na concepção que entende o Brasil como parte do mundo ocidental, porém a parte ainda atrasada. A posição do país é pensada, assim, em relação aos outros países. A partir desse pressuposto, a superação do atraso passa a ser o objetivo principal do desenvolvimento por ele proposto. Para a mesma autora, o desenvolvimentismo visa, em última análise, à integração mais dinâmica do país ao sistema capitalista mundial, sendo a nação considerada como parte desse sistema. A soberania decorre da igualdade às nações ricas e democráticas. O conceito de nação tem, nesse sentido, uma dimensão muito mais econômica do que política. O desenvolvimento eco-

\footnotetext{
${ }^{8}$ Associação de empresas nacionais e estrangeiras. "Do ponto de vista do empresário nacional, dadas as facilidades que o governo dá ao capital estrangeiro, passa a ser conveniente a associação, além do mais porque lhe permite baixar os custos de produção também pela incorporação de tecnologia mais avançada. Da perspectiva do empresário estrangeiro, a associação não só mantém os benefícios da legislação protecionista da importação de capital, como retira as dificuldades com que possivelmente se defronta por ser estrangeiro" (CARDOSO, 1978).
} 
nômico, empunhando a bandeira do combate ao atraso e à miséria, surge como "redenção nacional" (CARDOSO, 1978).

\section{Considerações finais}

No contexto brasileiro dos anos 1950, o crescimento acelerado da década, aliado à crise que se afigurava, na segunda metade do período, levaram à intensificação dos debates sobre o modelo de desenvolvimento a ser adotado, a fim de garantir a continuidade do crescimento, fazendo ressurgir o debate entre liberais e antiliberais que, nos anos 1940, popularizou-se como entreguistas versus nacionalistas.

Importante enfatizar que todas as discussões acerca do desenvolvimento - posturas analíticas, estratégias propostas, grupos envolvidos -, divergiam sobre o modelo de desenvolvimento para o país, mas nunca quanto ao significado do desenvolvimento. Ele era um fenômeno tido como universal e inquestionável.

Independentemente do modelo defendido, de uma forma geral, a ideologia do desenvolvimento tinha por base a busca da integração do Brasil ao mundo ocidental capitalista, tendo como objetivo central a superação do atraso. A idéia-força atraso versus desenvolvimento permeou, assim, todas as discussões sobre o tema e foi a base para a consolidação da ideologia desenvolvimentista que se afirmava como dominante no período ora estudado. Mesmo levando em consideração a especificidade do conceito desenvolvimentismo, essa ideologia permanece em conformidade com a ideologia geral do desenvolvimento, que visa, em última análise, à expansão do sistema capitalista para sua própria manutenção.

\section{Referências}

BANDEIRA, Muniz. Presença dos Estados Unidos no Brasil. Rio de Janeiro: Civilização Brasileira, 1973.

BIELSCHOWSKI, Ricardo. O pensamento econômico brasileiro: o ciclo ideológico do desenvolvimento. 3. ed. Rio de Janeiro: Contraponto, 1996.

CARDOSO, Miriam Limoeiro. Ideologia do Desenvolvimento - Brasil: JK - JQ. Rio de Janeiro: Paz e Terra, 1978.

DEVÉS VALDÉS, Eduardo. El pensamiento latinoamericano em el siglo XX: desde la CEPAL al neoliberalismo 1950-1990. Buenos Aires: Biblos, 2003. v. 2.

FURTADO, Celso. Desenvolvimento e Subdesenvolvimento. Rio de Janeiro: Fundo de Cultura, 1961.

GORENDER, Jacob. A Burguesia Brasileira. São Paulo: Brasiliense, 1983.

HOBSBAWN, Eric. A Era dos Extremos: O breve século XX - 1914-1991. São Paulo: Cia. das Letras, 1995. 
MALAN, Pedro Sampaio. Relações Econômicas Internacionais do Brasil: (1945-1964). In: PIERUCCI, Antônio Flávio de Oliveira et al. O Brasil Republicano: Economia e Cultura (1930-1964). Rio de Janeiro: Bertrand do Brasil, 1995. (História Geral da Civilização Brasileira. T. 3, v. 4).

NEVES, Lucília Almeida. In: BENEVIDES, Maria Vitória. O governo Kubischek: O desenvolvimento econômico e estabilidade política - 1956-1961. Rio de Janeiro: Paz e Terra, 1976.

PINHO, Diva Benevides. Aspectos do pensamento econômico do Brasil: 1940-1960. São Paulo: IPE/USP, 1986.

SALLUM JÚNIOR, Brasilio. A Condição Periférica: O Brasil nos quadros do capitalismo mundial (1945-2000). In: MOTA, Carlos Guilherme (Org.) Viagem Incompleta: a experiência brasileira (1500-2000) - A grande transação. São Paulo: SENAC, 2000.

SILVA, Heloisa Conceição Machado da. Da Substituição de importações à substituição de exportações: a política de Comércio exterior brasileira de 1945 a 1979. Porto Alegre: UFRGS, 2004. 